sedatives of any kind. The application of leeches to the region of the uterus, appeared, in a recent case of mania complicated with puerperal convulsions, to be attended with the most striking benefit after all other means had been tried without effect. Sedatives have been recommended to be applied to the cervix uteri, or thrown up into the rectum during labor, and after delivery, in cases of puerperal convulsions, but 1 have had no experience of their efficacy.-London Medical Gazette.

\title{
EFFECTS OF LEAD.
}

From Dr. Seymour's Olinique at St. Georgo's Eospital.

There are many trades and callings in which the use of lead is very extensive. This mineral poison inay get into the system by inhalation. Its first perceptible poisonous effect is upon the muscular structures, which lose their contractile power and become flabby and diminished in volume. The muscular coats of the intestinal canal are those which are generally first affected, some portions of them being dilated whilst others are contracted. Constipation arises from this, accompanied with great pain and spasmodic action of the recti muscles. In its early stage this colicky attack of the bowels is very easily relieved by the warm bath and doses of castor oil. Some physicians have recommended opium and remedies of that class, but castor oil is, after all, the very best. By the judicious employment of these means the affection may be removed, but if the patient returns immediately to his work it recurs in an aggravated form; the muscles of the arm become paralyzed, and it "drops," as it is termed. A similar effect may be produced by an over-exertion of these muscles, as occurs in some trades, such as those of shoemakers, cobblers, \&c. The morle of curing such affections as these is to abstain from the occupations which cause them; using a generous diet; resting the hand upon a splint, as in this man's case; and, best of all, by the employment of electricity. In addition to the use of these several means, this man was ordered to take half a drachm of the balsam of Peru three times daily, a remedy which has been supposed to be very useful, and I have certainly seen it of great service in cases in which over-exertion of the muscles has caused the paralysis. But this is not all. If the patient should be compelled by circumstances to return to his occupation and again inhale the poison, he will have accumulations of synovia in the joints, producing a species of synovial rheumatism, which will only yield to rest, local pressure, gnod food, and the occasional use of the warm bath ; though sometimes cases of this kind occur which require the same active treatment as severe idiopathic rheumatism. Should the same cause of disease be still in operation, a species of bronchitis, resembling bronchial phthisis, supervenes, in which the patient spits up large quantities of fawn-colored matter. On this state of things a more fearful disease than all, epilepsy, may supervene, and then death soon ensues.

Colica Pictonum.-A man up stairs labors under this imbibition of lead into the system. All persons who use paint in which lead is an in- 
gredient, such as coach painters and color grinders, are very liable to this affection. The peculiar name of colic which has been given to it arises from the first impression of the disease being made upon the muscular coat of the intestines. The best remedy for relieving the incipient stage is frequent doses of castor oil, which will evacuate the bowels freely, remove any foul collection that they may contain, and thereby diminish the muscular spasm. Some surgeons give calomel and opium in these cases, because opium has the great property of removing spasm, and this I dare say it certainly does efficiently, but I have very rarely had occasion to use it, having found castor oil answer every purpose. But this disease may proceed further, as in the patient up stairs, who was here for the same affection three months since. He then went out cured and returned to his work, which was a tacit invitation to the disease to return. He has now got what is technically termed the "hand-drop," which arises from a species of paralysis of the extensor muscles of the fore-arm, whereby the hand falls downward, and the sufferers are unable, by hitching and lifting, to bring it up. The best remedies for this stage are, first, to extend the arm and hand upon a splint, thus keeping the muscles at rest, and stimulating their non-contractile power by electricity. Shocks are the best means of applying this remedy, which is generally successful. Beyond this stage, however, the disease will proceed if the same cause be brought again into operation. The bronchial tubes will become affected, and an affection closely analogous to bronchial phthisis will produce rapid debility, and, finally, epileptic fits, and under these depressing causes the patient dies, completely worn out. This inan, however, has not reached this extreme stage, and although at present very ill, I do not doubt of his ultimate recovery. - London Lancet.

\section{EMPLOYMENT OF BLISTERS.}

By Waltor O. Dendy, Esq., Surg.

Probarly one of the most common errors in the practice of medicine is the indiscrimination between the use and abuse of a remedy. On its success in any one case, the physician often hastily promulgates its value, and it is then adopted with avidity, without judgment or reflection on the principles of pathology. Witness iodine, creosote, veratria, et id genus omne. This must be a common source of disappointment.

Regarding doses and periods, also, there is often so little rule observed, as to bring really valuable remedies, especially those of great power, into disuse, and even disgrace; for it may be almost an axiom that the more valuable the use of a remedy, the more perilous is its abuse. In justice to your columns I will not dilate on this point, but will merely allude to a fact regarding the application of blisters in the inflanmatory affections of the chest, abdomen or heid, in children. I consider these applications of the highest value, especially where sanguineous depletion cannot be adopted or repeated, and in the second stages of pueumonia, meningitis, \&c. One error of their employment has been too close a locality to the 